\title{
A Simple Approach to Dynamic Material Balance in Gas-Condensate Reservoirs
}

\author{
M. Heidari Sureshiani*, S. Gerami and M.A. Emadi \\ IOR Research Institute, NIOC, 22 Negar St., Vanak Sq., Tehran - R.I. d'Iran \\ e-mail: m.heidari.su@gmail.com - sgerami@gmail.com - emadi@nioc.rtd.ir \\ * Corresponding author
}

\begin{abstract}
Résumé - Une approche simple pour un équilibre dynamique des matières dans des réservoirs de gaz-condensat - Lors de calculs traditionnels d'équilibre de matières, des données de pression de puits fermé sont utilisées pour déterminer une pression moyenne du réservoir, tandis que des techniques récentes n'exigent pas que le puits soit fermé et utilisent à la place des données de valeur de pression de puits en écoulement. Ces méthodes, connues sous le nom d'équilibre "dynamique" de matières, sont développées pour un écoulement monophasique (huile ou gaz) dans les réservoirs. Toutefois, l'utilisation de telles méthodes pour des réservoirs de condensats de gaz peut générer des erreurs significatives en matière de prédiction de pression moyenne du réservoir du fait de la transgression de l'hypothèse de phase unique dans de tels réservoirs. Au cours de travaux précédents, une méthode destinée à l'analyse de données de production dans les réservoirs de condensats de gaz a été développée. La méthode exigeait un taux de production de gaz standard, un rapport gaz-huile de production, une pression de puits en écoulement, des données de CVD (Constant Volume Depletion) et des courbes de perméabilité relative. Le présent article présente une nouvelle technique n'ayant pas besoin des courbes de perméabilité relative et de la pression du puits en écoulement. Par cette méthode, le rapport gaz-huile de production est interpolé à partir des données $R_{v}$ en fonction de la pression $p$ dans le tableau de CVD et la pression correspondante est localisée. Le paramètre $p / z_{t p}$ est alors évalué en des points de pression déterminés et il est tracé en fonction de $n_{p}$ qui forme une ligne droite. La nature de ce tracé est telle que son extrapolation au point où $p / z_{t p}=0$ donnera le nombre de moles initial en place. En mettant $p_{i} / z_{t p, i}$ (paramètre connu) et un $n_{i}$ estimé dans l'équation d'équilibre de matières, une pression moyenne de réservoir peut être déterminée. La méthode repose sur une hypothèse principale selon laquelle la région, où à la fois les phases gazeuses et le condensat sont mobiles, est de dimensions négligeables par rapport au réservoir. L'approche est plutôt simple et les calculs sont beaucoup plus faciles que dans le cadre des travaux précédents. Elle procure un outil d'ingénierie pratique pour des études industrielles puisqu'elle exige des données qui sont généralement disponibles lors d'opérations normales de production. Toutefois, elle n'est applicable que lorsque la pression moyenne de réservoir approche la pression de point de rosée et chute plus bas que celle-ci. La méthodologie est validée en utilisant des données synthétiques de production provenant de plusieurs exemples. De plus, la méthode est évaluée par le biais d'une estimation de la pression moyenne de réservoir et du gaz d'origine en place à partir de données de champs réels. Les résultats montrent un assez bon accord en matière de gaz en place pour ce champ entre cette nouvelle méthode et le calcul volumétrique.
\end{abstract}

Abstract - A Simple Approach to Dynamic Material Balance for Gas-Condensate Reservoirs In traditional material balance calculations, shut-in well pressure data are used to determine average reservoir pressure while recent techniques do not require the well to be shut-in and use instead flowing well pressure-rate data. These methods, which are known as "dynamic" material balance, are developed 
for single-phase flow (oil or gas) in reservoirs. However, utilization of such methods for gas-condensate reservoirs may create significant errors in prediction of average reservoir pressure due to violation of the single-phase assumption in such reservoirs.

In a previous work, a method for production data analysis in gas-condensate reservoirs was developed. The method required standard gas production rate, producing gas-oil ratio, flowing well pressure, CVD data and relative permeability curves. This paper presents a new technique which does not need relative permeability curves and flowing well pressure. In this method, the producing oil-gas ratio is interpolated in the vaporized oil in gas phase $\left(R_{v}\right)$ versus pressure $(p)$ data in the CVD table and the corresponding pressure is located. The parameter pressureltwo-phase deviation factor $\left(p / z_{t p}\right)$ is then evaluated at the determined pressure points and is plotted versus produced moles $\left(n_{p}\right)$ which forms a straight line. The nature of this plot is such that its extrapolation to point where $p / z_{t p}=0$ will give initial moles in place. Putting initial pressure/initial two-phase deviation factor $\left(p_{i} / z_{t p, i}\right)$ (known parameter) and estimated initial moles $\left(n_{i}\right)$ into the material balance equation, average reservoir pressure can be determined. A main assumption behind the method is that the region where both gas and condensate phases are mobile is of negligible size compared to the reservoir. The approach is quite simple and calculations are much easier than the previous work. It provides a practical engineering tool for industry studies as it requires data which are generally available in normal production operations. However, it is only applicable when average reservoir pressure approaches dew point pressure and falls below it.

The methodology is validated using synthetic production data for several examples. In addition, the method is evaluated through estimation of average reservoir pressure and original gas in place from actual field data. The results show a fairly good agreement in gas in place obtained from the new method and that of volumetrically calculated value for this field.

\section{NOMENCLATURE}

$B \quad$ Formation volume factor

$b_{p s s} \quad$ Parameter defined by Equation (3)

c Compressibility

G Initial gas in place

$h \quad$ Reservoir thickness

$k \quad$ Absolute permeability

$k_{r g} \quad$ Gas relative permeability

$k_{r o} \quad$ Oil relative permeability

$m \quad$ Single-phase pseudopressure

$m_{t p} \quad$ Two-phase pseudopressure

n Moles

$n_{p} \quad$ Produced moles

$p \quad$ Pressure

$p_{0}$

$p_{\text {dew }}$

$q_{g s c}$

$q_{m}$

$r_{e}$

$r_{w}$

$R_{p}$

$R_{s}$

$R_{v}$

$S$

$t$

$t_{a c r}$

$t_{a, t p}$

\section{Pressure}

Reference pressure

Dew point pressure

Standard volumetric gas flow rate

Molar gas flow rate

Reservoir external radius

Wellbore radius

Producing gas-oil ratio

Solution gas in oil phase

Vaporized oil in gas phase

Saturation

Time

Material balance pseudotime

Two-phase pseudotime

$\begin{array}{ll}t_{a c r, t p} & \text { Two-phase material balance pseudotime } \\ z & \text { Deviation factor } \\ z_{t p} & \text { Two-phase deviation factor } \\ \mu & \text { Viscosity } \\ \rho & \text { Molar density } \\ \rho_{g s c} & \text { Molar density of gas component at standard con- } \\ & \text { ditions } \\ \rho_{\text {osc }} & \text { Molar density of oil component at standard condi- } \\ & \text { tions }\end{array}$

\section{Subscripts}

eff Effective with respect to initial water saturation

$g \quad$ Gas phase

ave. Average

$i \quad$ Initial

$o \quad$ Oil phase

$w \quad$ Water phase

wf Well flow

\section{INTRODUCTION}

Material balance calculations are performed during the production life of the reservoirs to determine hydrocarbon in place. This information is crucial for reservoir management and decision making for field development. The reserves can be determined using volumetric method, material balance method and/or production decline techniques. Among these methods, the material balance is accepted to be the most accurate way for estimating original hydrocarbon in place. 
There is a basic assumption behind material balance calculations which considers the reservoir to be depleted in a tank-type manner, i.e. the pressure dependent properties across the reservoir are evaluated at an equivalent pressure which is the average reservoir pressure. The pressure dependent properties could be fluid and rock properties. The volume expansion of rock and fluid should be known as a function of pressure to account for their volume changes when balancing total mass entering and total mass exiting the reservoir.

For volumetric dry gas reservoirs, a simple plot of $p / z$ evaluated at average reservoir pressure versus cumulative gas production forms a straight line starting from initial pressure, $p_{i} / z_{i}$, going to original gas in place. Deviations from the straight line are due to external recharge or offset drainage. For volumetric gas-condensate reservoirs, a plot of $p / z_{t p}$ calculated at average reservoir pressure versus cumulative produced moles of fluids gives initial moles in place and ultimately - initial gas in place. To prepare such a plot, average reservoir pressure must be known as a function of time. Traditionally, static tests are implemented at several points during the production life of the wells which requires the well to be shut-in for certain time intervals. Consequently, there will be loss of production and emergence of additional costs associated with the operations. Quite often, the duration of shut-in is not long enough (especially in tight formations) to directly measure the average reservoir pressure and extrapolation techniques are needed. This can result in an additional problem due to possible wrong interpretations and improper tests knowing that the tests and interpretations are much more difficult for gas-condensate reservoirs. In addition, for conditions of asphaltene precipitation in wellbore during shut-in time, the static pressure data cannot be acquired.

In 1998, the concept of "Flowing" material balance was introduced by Mattar and McNeil (1998). In a flowing material balance procedure, the flowing well pressure data along with the cumulative production (constant rate production) are analyzed to determine original fluid in place and average reservoir pressure. The important feature of this technique is that it does not require the well to be shut-in (no need to static tests). Instead of average reservoir pressure data, it uses flowing well pressure data which are normally available in production operations. Thus it provides a very practical tool for estimating hydrocarbon (oil or gas) in place. The method was further extended to the case of variable well rate conditions known as "Dynamic" material balance (Mattar and Anderson, 2005). For variable well rate conditions, the flow time must be replaced by Material Balance Time (Blasingame and Lee, 1986; Palacio and Blasingame, 1993). In this work, we show that the methods of dry gas reservoirs for dynamic material balance of gas-condensate systems may introduce enormous errors in estimation of average pressure and gas in place and this is due to presence of two phases in a gas-condensate reservoir.
The authors recently developed a method for estimating original gas in place and average reservoir pressure of gascondensate reservoirs with the analysis of well production data (Heidari Sureshjani and Gerami, 2011). They proposed a boundary dominated flow equation and two-phase material balance pseudotime for gas-condensate systems and coupled them with a material balance equation to estimate gas in place and average reservoir pressure through an iterative procedure. However, the method has some practical limitations. It needs relative permeability data which may not be always available to reservoir engineers and even if available, it is somehow uncertain information which may not be a representative one for the two-phase flow region. Furthermore, the calculations were to some extent complex. In the current study, we present a very simple technique which is much easier, although less accurate, than the previous method. It does not need relative permeability curves and flowing well pressure data for analysis.

\section{DRY GAS DYNAMIC MATERIAL BALANCE}

For gas wells producing under variable pressure-rate conditions, average pseudopressure can be determined from the following equation (Mattar and Anderson, 2005):

$$
m_{\text {ave. }}(t)=m_{w f}(t)+q_{m}(t) b_{p s s}
$$

where:

$$
\begin{gathered}
m=\int_{p_{0}}^{p} \frac{\rho}{\mu} d p \\
b_{p s s}=\frac{1}{2 \pi k_{e f f} h}\left(\ln \frac{r_{e}}{r_{w}}-\frac{3}{4}\right)
\end{gathered}
$$

Once $m_{\text {ave }}$ is determined, average pressure can be interpolated from the PVT table of $p$ versus $m$. The parameter $p / z_{t p}$ is then evaluated at the determined average pressure and is plotted versus $G_{p}$ which forms a straight line. Extrapolation of this plot to point where $p / z_{t p}=0$ will give initial gas in place, as the following equation demonstrates:

$$
\left(\frac{p}{z}\right)_{\text {ave. }}=\left(\frac{p}{z}\right)_{i}\left(1-\frac{G_{p}}{G}\right)
$$

In case that $b_{p s s}$ is not known ( $r_{e}$ and $k_{e f f} h$ are not known), the following boundary dominated flow equation can be used to determine this parameter (Palacio and Blasingame, 1993):

$$
\frac{m_{i}-m_{w f}}{q_{m}}=b_{p s s}+\frac{1}{G B_{g i} \mu_{g i} c_{g i}} t_{a c r}
$$

where:

$$
t_{a c r}=\frac{\int_{0}^{t} \frac{\mu_{g i} c_{g i}}{\mu_{g} c_{g}} q_{m}(\tau) d \tau}{q_{m}(t)}
$$


From the intercept of a linear plot of $\left(m_{i}-m_{w f}\right) / q_{m}$ versus $t_{a c r}, b_{p s s}$ can be obtained. Also, from the slope of this plot $G$ can be determined.

\section{GAS-CONDENSATE DYNAMIC MATERIAL BALANCE}

\subsection{Previous work}

For a well located in the center of a cylindrical gas-condensate reservoir, we can use the following flowing material balance equation proposed by Fevang and Whitson (1995) and further investigated by Heidari Sureshjani and Gerami (2011):

$$
m_{t p, a v e .}(t)=m_{t p, w f}(t)+q_{g s c}(t) b_{p s s}
$$

where:

$$
m_{t p}=\int_{p_{\text {dew }}}^{p}\left(\frac{k_{r g}}{\mu_{g} B_{g}}+\frac{k_{r o}}{\mu_{o} B_{o}} R_{s}\right) d p
$$

Parameter $b_{p s s}$ is the same as Equation (3) except $k_{\text {eff }}$ should be replaced by $k$. The boundary dominated flow equation for gas-condensate reservoirs is given as follows (Heidari Sureshjani and Gerami, 2011):

$$
\frac{m_{t p, i}-m_{t p, w f}}{q_{g s c}}=b_{p s s}+\frac{\left(1-S_{w i}\right) m_{t p, i}}{G B_{g i}} t_{a c r, t p}
$$

In Equation (9), the two-phase material balance pseudotime is expressed as:

$$
t_{a c r, t p}=\frac{\int_{0}^{t_{a, t p}} q_{g s c}(\tau) d \tau}{q_{g s c}}
$$

where $t_{a, t p}$ is two-phase pseudotime and is defined as:

$$
t_{a, t p}=\frac{1}{m_{t p, i}} \int_{0}^{t} \frac{d t}{\left[\frac{\partial}{\partial m_{t p}}\left(\frac{S_{g}}{B_{g}}+\frac{S_{o}}{B_{o}} R_{s}\right)\right]_{p_{\text {ave }} .}}
$$

From Equation (9), it is seen that a plot of: $\left(m_{t p, i}-m_{t p, w f}\right) / q_{g s c}$ versus $t_{a c r, t p}$ should yield a straight line when boundary dominated flow is reached. From the slope and intercept of this line, $G$ and $b_{p s s}$ can be estimated, respectively. However, $t_{a, t p}$ which is required in calculation of $t_{a c r, t p}$ is a function of average reservoir pressure. Therefore, an auxiliary equation, which is material balance equation, is needed. It is written as (Hagoort, 1988; Vo et al., 1990):

$$
\left(\frac{p}{z_{t p}}\right)_{p_{\text {ave. }}}=\left(\frac{p}{z_{t p}}\right)_{p_{i}}\left(1-\frac{n_{p}}{n_{i}}\right)
$$

Coupling the above equations and going through an iterative procedure will yield average reservoir pressure and original gas in place.

\subsection{Present Approach}

In this section a simple approach is introduced for estimating average reservoir pressure and original gas in place and this is the purpose of this study. The main simplification underlying the method is that we can divide the reservoir into two parts. The flow behavior in the inner part, where two phases are flowing, is assumed to be steady-state i.e. the molar percentage of compositions entering this region is equal to that of entering the well bore at a certain time. The fluid inside the outer region, where oil phase is immobile, is assumed to have average properties which are evaluated at average reservoir pressure and this part is depleted in a tank-type manner. The location of the interface boundary of these two regions is not necessarily constant. Since the flow in the inner region is steady-state and the oil phase in the outer region is immobile, the depletion behavior of the outer region can be simulated with a CVD test. However, the material balance assumes the entire reservoir to be a single cell and simulates the entire reservoir by CVD test. This will not introduce a considerable error because the size of steady state region is small compared to the outer part. Knowing that the inner part is steady state, the solution oil-gas ratio in the entering gas to this part is equal to the producing oil-gas ratio at each time (Fevang and Whitson, 1995; Mott, 2003). Therefore, we interpolate the producing oil-gas ratio in the $R_{v}$ versus $p$ data in the CVD table and locate the corresponding pressure. This pressure point is a rough estimation of average reservoir pressure at that time. We evaluate $p / z_{t p}$ at the determined pressure points and plot it versus $n_{p}$ which forms a straight line. The nature of this plot is such that its extrapolation to point where $p / z_{t p}=0$ will give initial moles in place. The produced moles are related to standard gas flow rate and producing gas-oil ratio using the following equation:

$$
n_{p}=\int_{0}^{t}\left(q_{g s c} \rho_{g s c}+\frac{q_{g s c}}{R_{p}} \rho_{o s c}\right) d t
$$

To estimate initial gas in place, we use the following equation:

$$
G=\frac{n_{i}}{\left(\rho_{g s c}+\rho_{o s c} R_{v i}\right)}
$$

Putting $p_{i} / z_{t p, i}$ (known parameter) and estimated $n_{i}$ into Equation (12), we can determine average reservoir pressure as a function of time. The procedure is summarized as follows:

- locate the pressures in CVD table where well producing oil-gas ratio is equal to $R_{v}$ in CVD test;

- calculate $p / z_{t p}$ using the obtained pressure data in the previous step. Plot $p / z_{t p}$ versus $n_{p}$. Extrapolate this line to the point where $p / z_{t p}=0$, the corresponding $n_{p}$ is regarded as initial moles in place;

- substitute $p_{i} / z_{t p, i}$ and estimated $n_{i}$ into Equation (12) to calculate average reservoir pressure.

In the above procedure, the required production data are $q_{g s c}$ and $R_{p}$ (no need for $p_{w f}$ ). 


\section{VERIFICATION}

To verify the presented method, several synthetic production data have been generated using fine grid compositional simulations. The positive coupling and inertial effects have been activated in the simulator. The generated production data were analyzed with the outlined procedure to obtain gas in

TABLE 1

Basic reservoir properties

\begin{tabular}{c|c}
\hline Thickness (m) & 100 \\
\hline Well bore radius (m) & 0.1 \\
\hline Reservoir external radius (m) & 1000 \\
\hline Porosity (fraction) & 0.12 \\
\hline Permeability (md) & 20 \\
\hline Forchheimer parameter for Set A (1/m) & $2.7864 \times 10^{9}$ \\
\hline Forchheimer parameter for Set B $(1 / \mathrm{m})$ & $1.7732 \times 10^{9}$ \\
\hline
\end{tabular}
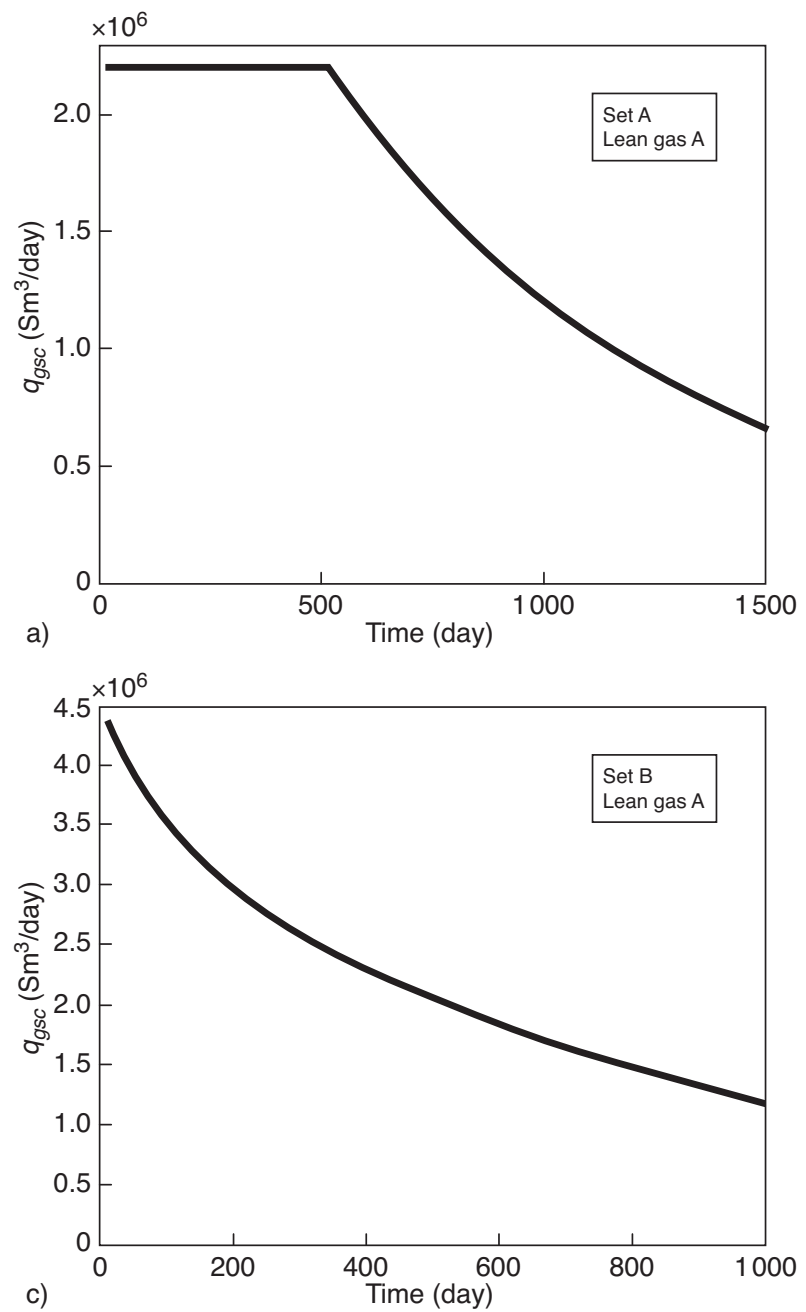

place and average reservoir pressure. We used two different fluids which are Lean gas A with maximum liquid dropout of $3.7 \%$ and Rich gas B with maximum liquid dropout of $27.33 \%$. Also two sets of immiscible relative permeability data were considered. Table 1 shows basic reservoir properties. Tables 2 and 3 provide the key fluid properties and compositions of fluids, respectively. In Table 4, information of immiscible relative permeability data is given. Totally four

TABLE 2

Key reservoir PVT properties

\begin{tabular}{c|c|c}
\hline & Lean gas A & Rich gas B \\
\hline Initial pressure (bar) & 210 & 260 \\
\hline Dew point pressure (bar) & 188.112 & 257.278 \\
\hline Reservoir temperature $\left({ }^{\circ} \mathrm{C}\right)$ & 93.333 & 93.333 \\
\hline Maximum CVD liquid dropout $(\%)$ & 3.7 & 27.33 \\
\hline Initial solution oil in gas $\left(\mathrm{Sm}^{3} / \mathrm{Sm}^{3}\right)$ & 0.000104535 & 0.000569580 \\
\hline
\end{tabular}
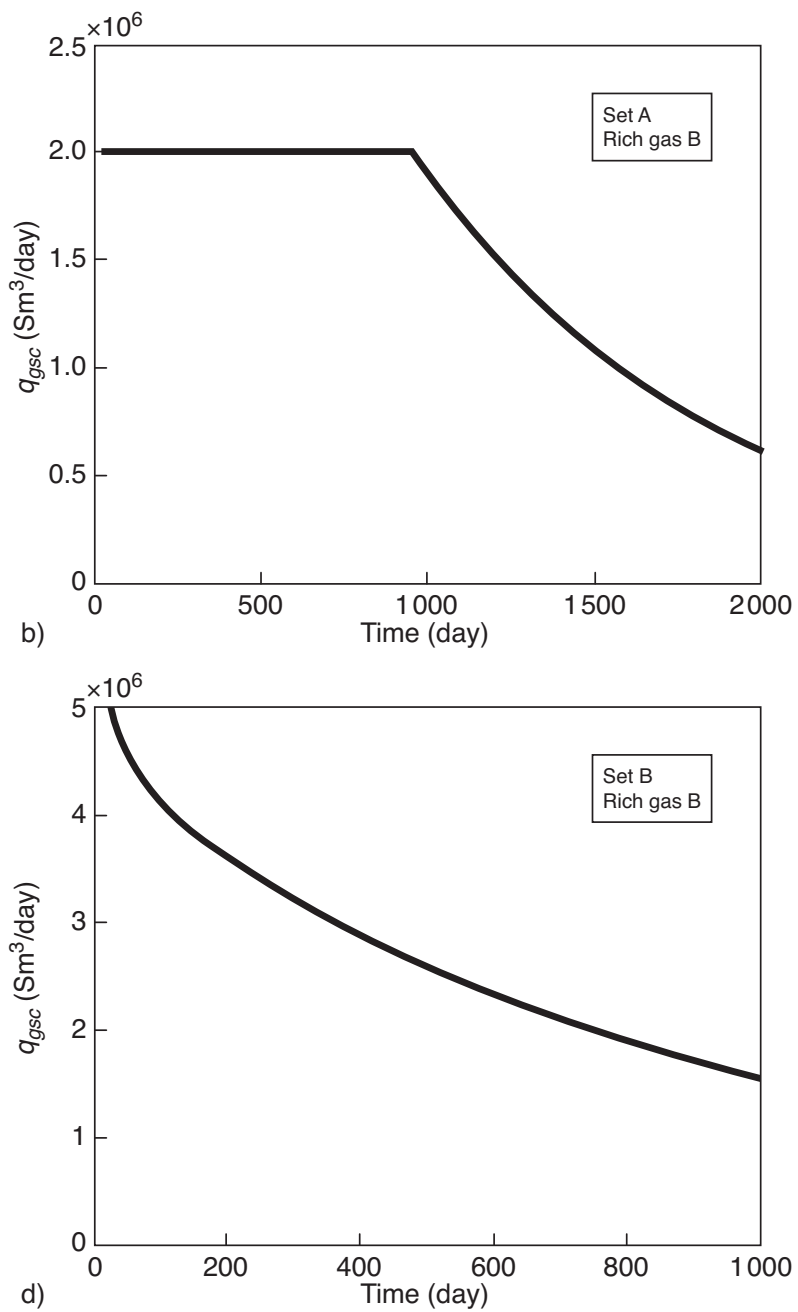

Figure 1

Gas flow rate for a) set A and Lean gas A; b) set A and Rich gas B; c) set B and Lean gas A; d) set B and Rich gas B. 
TABLE 3

Mixture overall compositions

\begin{tabular}{c|c|c}
\hline & Lean gas A & Rich gas B \\
\hline $\mathrm{C} 1$ & 83.2 & 78 \\
\hline $\mathrm{C} 4$ & 13 & 12 \\
\hline $\mathrm{C} 7$ & 3.1 & 7.2 \\
\hline $\mathrm{C} 10$ & 0.4 & 1.4 \\
\hline $\mathrm{C} 14$ & 0.3 & 1.4 \\
\hline
\end{tabular}

cases are analyzed which are made based on different combinations of the considered fluids and relative permeability data. Figures 1 and 2 show gas production rate and producing gas-oil ratio, respectively. In Figure $3, p / z_{t p}$ is evaluated at the pressure points calculated in the way as
TABLE 4

Key reservoir immiscible relative permeability properties

\begin{tabular}{l|c|c}
\hline & Set A & Set B \\
\hline Initial water saturation (\%) & 25 & 16 \\
\hline Critical oil saturation (\%) & 13 & 24 \\
\hline Maximum oil saturation (\%) & 75 & 84 \\
\hline Gas relative permeability at initial water saturation & 0.841258 & 0.80 \\
\hline Gas relative permeability at critical oil saturation & 0.557569 & 0.4 \\
\hline Oil relative permeability at maximum oil saturation & 0.834773 & 0.8 \\
\hline
\end{tabular}

mentioned in the first step of the outlined procedure and is plotted versus $n_{p}$. Figure 4 compares the estimated average reservoir pressure and simulated values. It is seen that the estimated values show very good match with the simulated points.
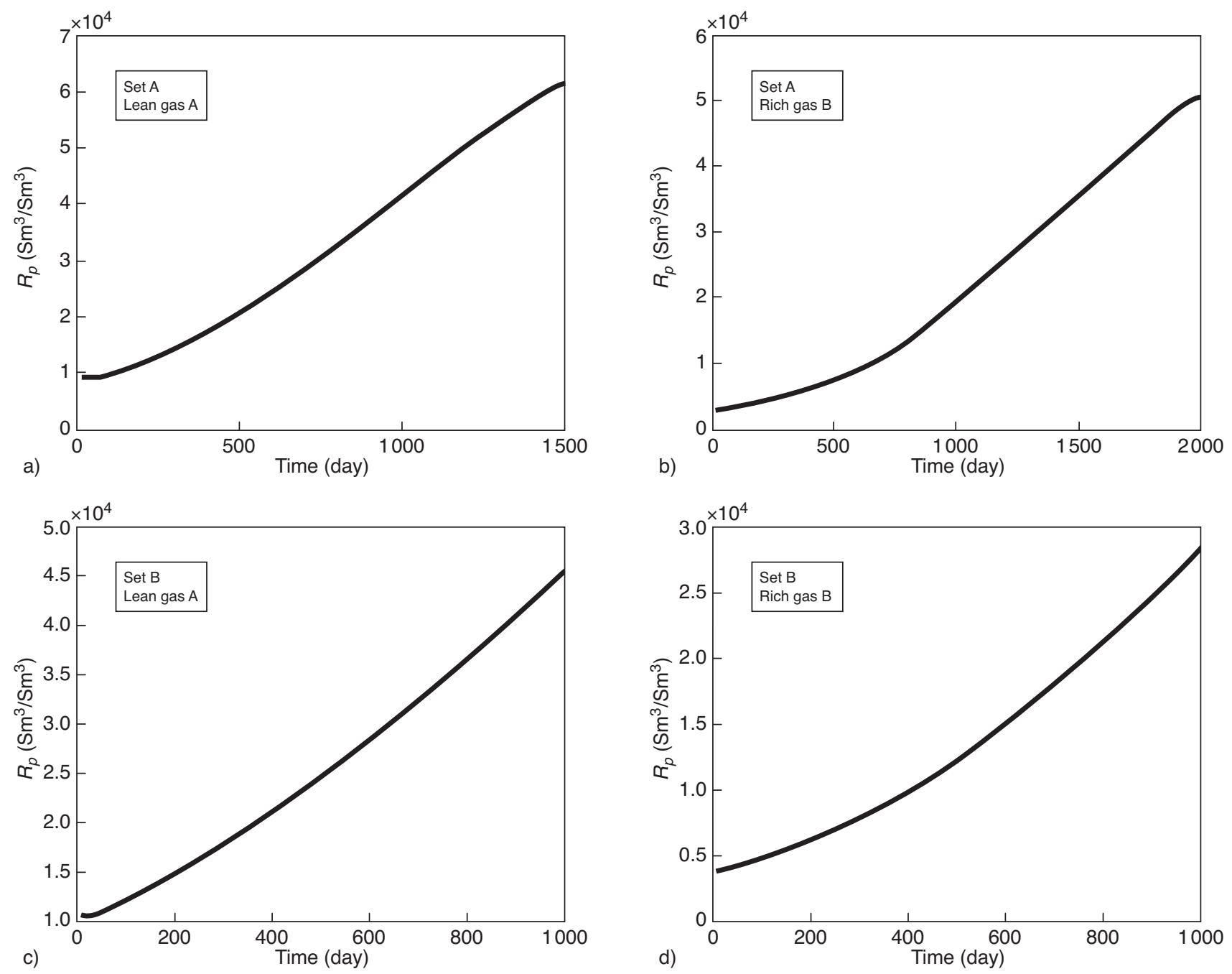

Figure 2

Producing gas-oil ratio for a) set A and Lean gas A; b) set A and Rich gas B; c) set B and Lean gas A; d) set B and Rich gas B. 

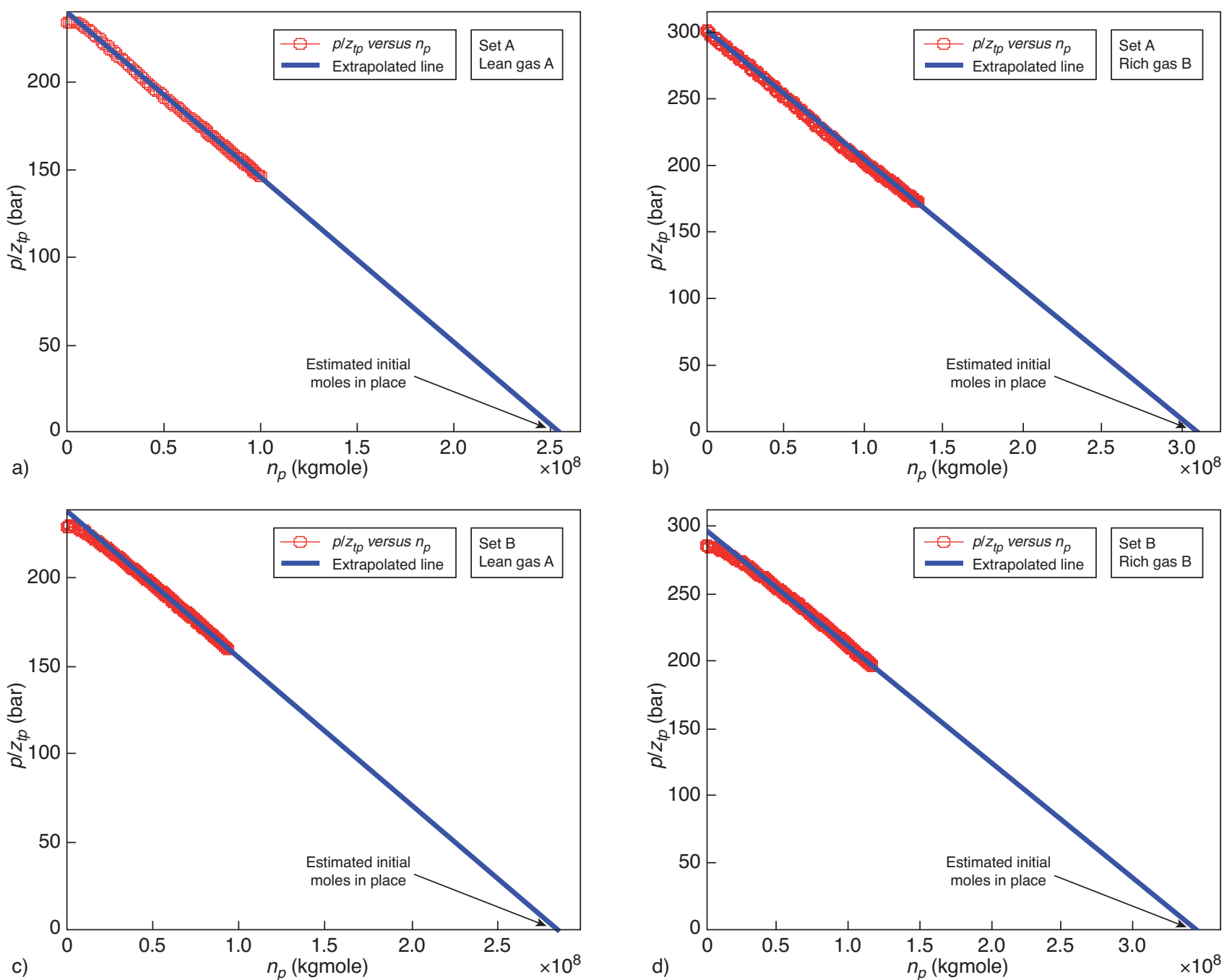

Figure 3

Plot of $p / z_{t p}$ evaluated at the pressures calculated in the first step of procedure versus cumulative mole production for a) set A and Lean gas A; b) set A and Rich gas B; c) set B and Lean gas A; d) set B and Rich gas B.

TABLE 5

Estimated $G\left(\mathrm{MMMSm}^{3}\right)$ for synthetic examples

\begin{tabular}{l|c|c|c|c|c}
\hline & \multirow{2}{*}{ Value } & \multicolumn{2}{|c|}{ Present approach } & \multicolumn{2}{c}{ Previous method } \\
\cline { 3 - 6 } & & Estimated & Error & Estimated & Error \\
\hline Set A - Lean gas A & 5.5550 & 5.8636 & 5.55 & 5.5672 & 0.22 \\
\hline Set A - Rich gas B & 6.2900 & 6.6691 & 6.03 & 6.0659 & 3.56 \\
\hline Set B - Lean gas A & 6.2216 & 6.5773 & 5.72 & 6.2994 & 1.25 \\
\hline Set B - Rich gas B & 7.0448 & 7.4580 & 5.86 & 6.6948 & 4.97 \\
\hline
\end{tabular}

Error $=100 \times$ I Estimated value - True value I / True value

Table 5 summarizes the true values, estimated values and errors for determination of $G$ using the present approach and also the previous method. As can be seen from this table, the introduced errors using the present approach are higher than those of the previous method. However, they are yet reasonable for engineering practices.

\section{DISCUSSION}

The main advantage of the current method compared to the previous one is its simplicity and the requirement for minimum input data. Gas production rate, producing gas-oil ratio and PVT information are usually available to reservoir engineers. However, synthetic examples reveal that the introduced errors using this method are a little higher than those of the previous work. In addition, in the former work we could be able to determine a parameter called " $b_{p s s}$ " which would give us some additional information (such as skin) about the reservoir. It is noted that the given procedure in this 

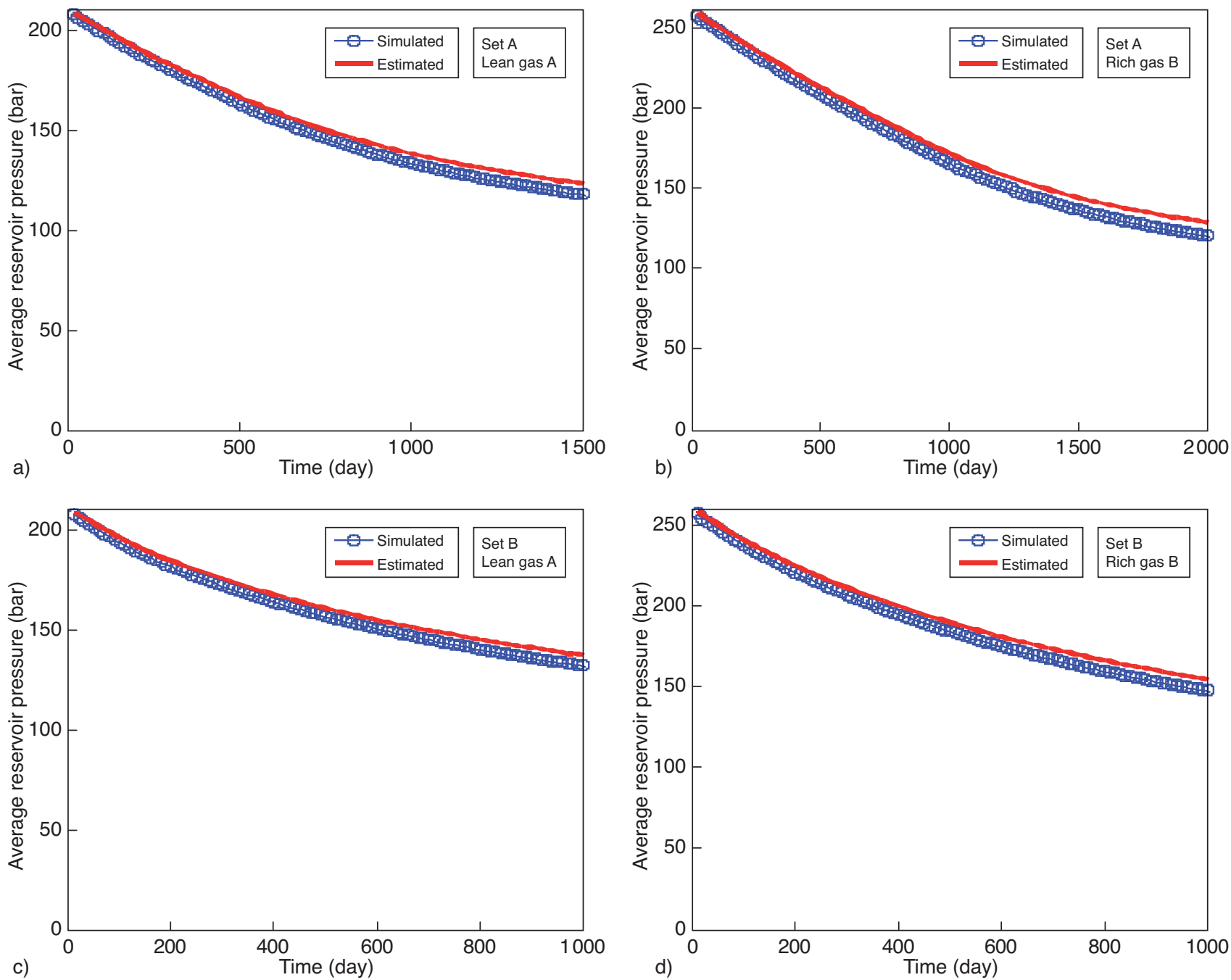

Figure 4

Average reservoir pressure for a) set A and Lean gas A; b) set A and Rich gas B; c) set B and Lean gas A; d) set B and Rich gas B. Comparison of proposed procedure and numerical simulation.

study is unable to analyze early part of production data (when average reservoir pressure is higher than dew pressure) while in the previous work as the pressure response reached the boundary, a plot of normalized two-phase pseudopressure versus two-phase material balance pseudotime would form a straight line and $G$ could be determined from the slope of this line. In summary, no one can conclude which method is superior to another as each of which may be applicable in different situations.

Likewise any other method, the mentioned method has its limitations. One limitation is its inability to analyze the production data when average reservoir pressure is considerably higher than dew point pressure (early part of data). However, the $p / z_{t p}$ data tend to form a straight line as the reservoir pressure approaches dew point pressure and falls below it.
In another word, we must observe variation of producing gas-oil ratio and this happens when condensate is formed in the bulk of the reservoir. The unusable early data are distinguished as a curved part in $p / z_{t p}$ plots and are ignored. This behavior can be observed in Figure 3. If the producing time is not long enough to observe a straight line, it would be a problem using this method. The duration of this period is long for large reservoirs and for reservoirs with significant difference between initial pressure and dew point pressure.

Fortunately, the dry gas approach can be used for early time of production provided that sandface pressure remains above dew point pressure. For analyzing production data of dry gas reservoirs, a plot of normalized single-phase pseudopressure versus material balance pseudotime will form a straight line in boundary dominated flow period and from the 


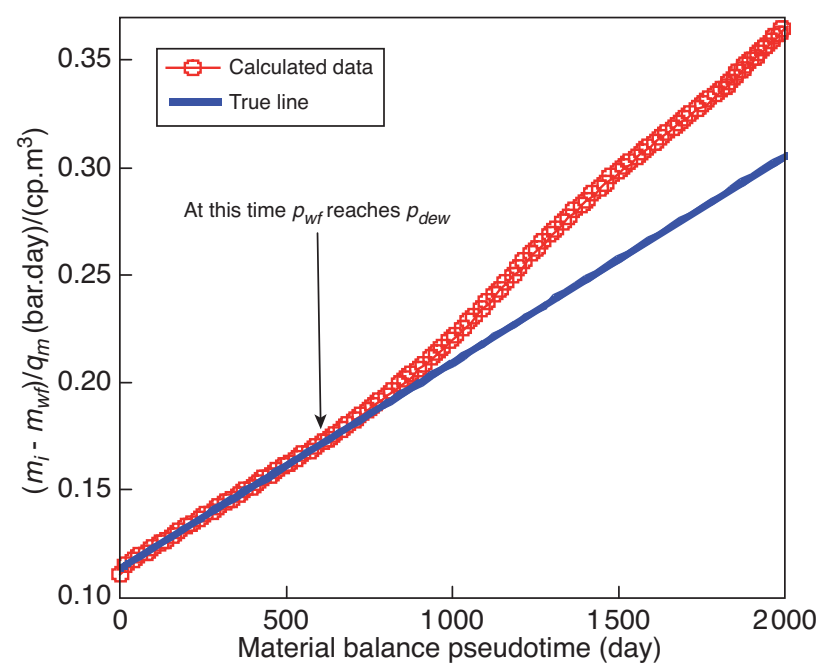

Figure 5

Normalized single-phase pseudopressure versus material balance pseudotime. Deviation occurs from true straight line as the sandface pressure approaches dew point pressure and falls below it.

slope of this line $G$ can be estimated. In a gas-condensate reservoir, such a plot deviates from the straight line as the sandface pressure reaches dew point pressure and the deviation becomes very severe as time goes by. To observe such behavior, $r_{e}$ has been doubled in case Set A and Lean gas A so that such behavior can be clearly observed. Deviation from the straight line can be seen in Figure 5. As shown in this figure, the dry gas approach works best in the region where sandface pressure is still above dew point pressure. For reservoirs with smaller $r_{e}$, this region may be very small and sometimes unrecognizable. We conclude that in the early part (for times when $p_{w f}>p_{d e w}$ ) of the regions where the proposed simple approach is unusable, the dry gas approach may be applicable. In the period when $p_{w f}$ is below $p_{\text {dew }}$ and reservoir pressure is still above $p_{\text {dew }}$, neither dry gas approach nor the introduced method can be used for analysis of production data in gas-condensate reservoirs.

\section{APPLICATION TO A FIELD EXAMPLE}

To demonstrate the applicability of the method, we have analyzed the production data of gas-condensate field X. Several wells have been drilled in this field but there were only two active wells named "X2" and "X3". For some periods of time, the wells have been closed following 20 years of production. Figures 6 and 7 show the cumulative gas production and producing gas-oil ratio for these wells. Using the above described procedure, $p / z_{t p}$ versus $n_{p}$ is plotted for both wells and a straight line is fitted to the obtained points, as indicated

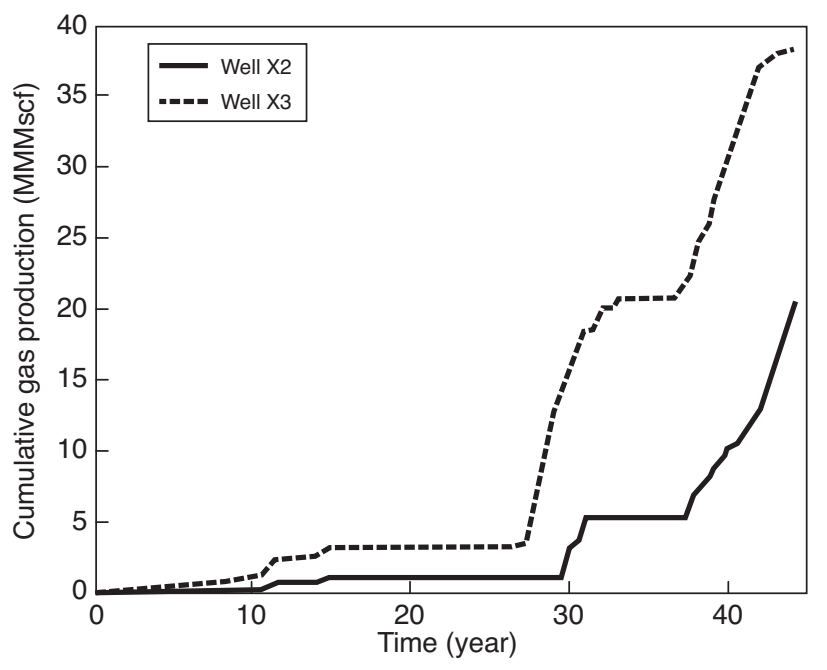

Figure 6

Cumulative gas production of wells X2 and X3.
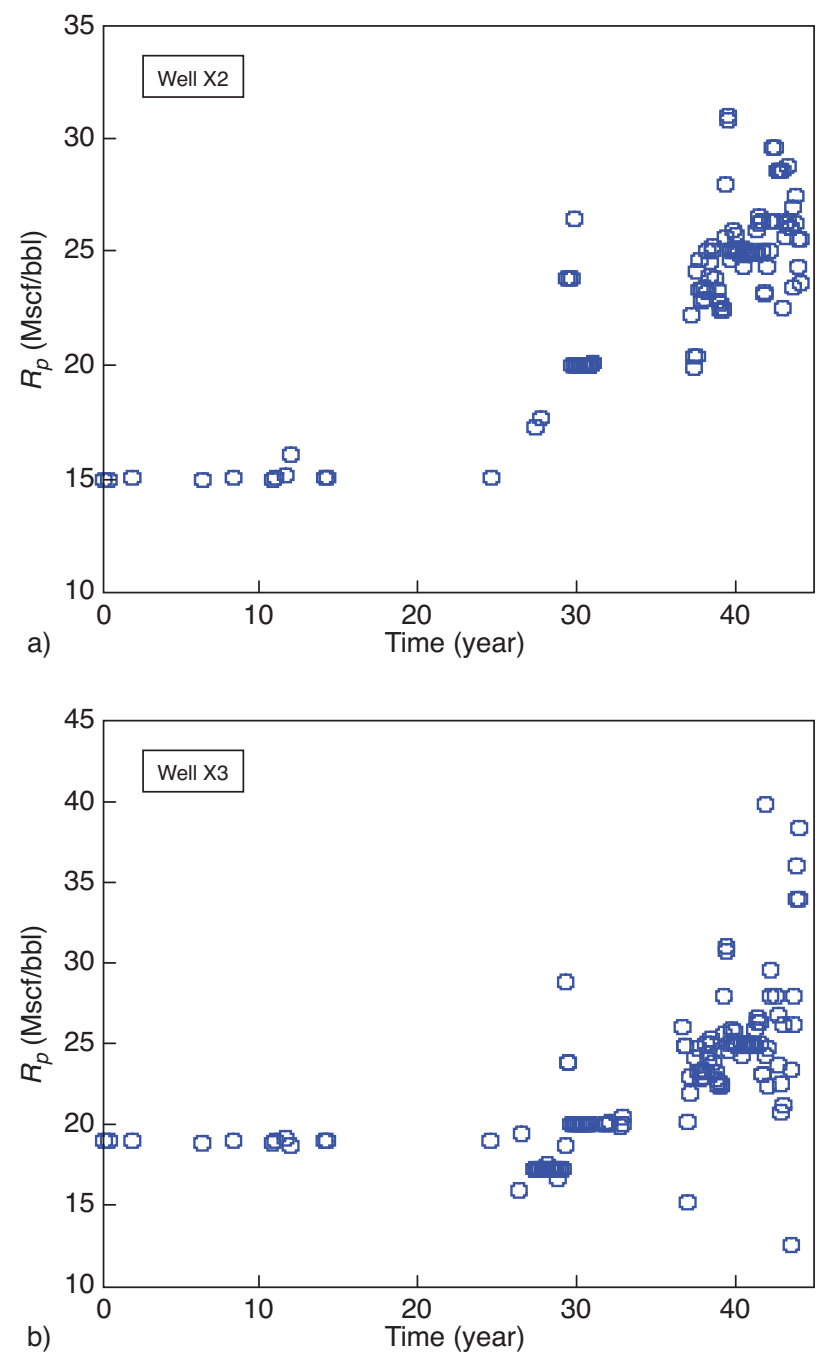

Figure 7

Producing gas-oil ratio of a) well X2; b) well X3. 

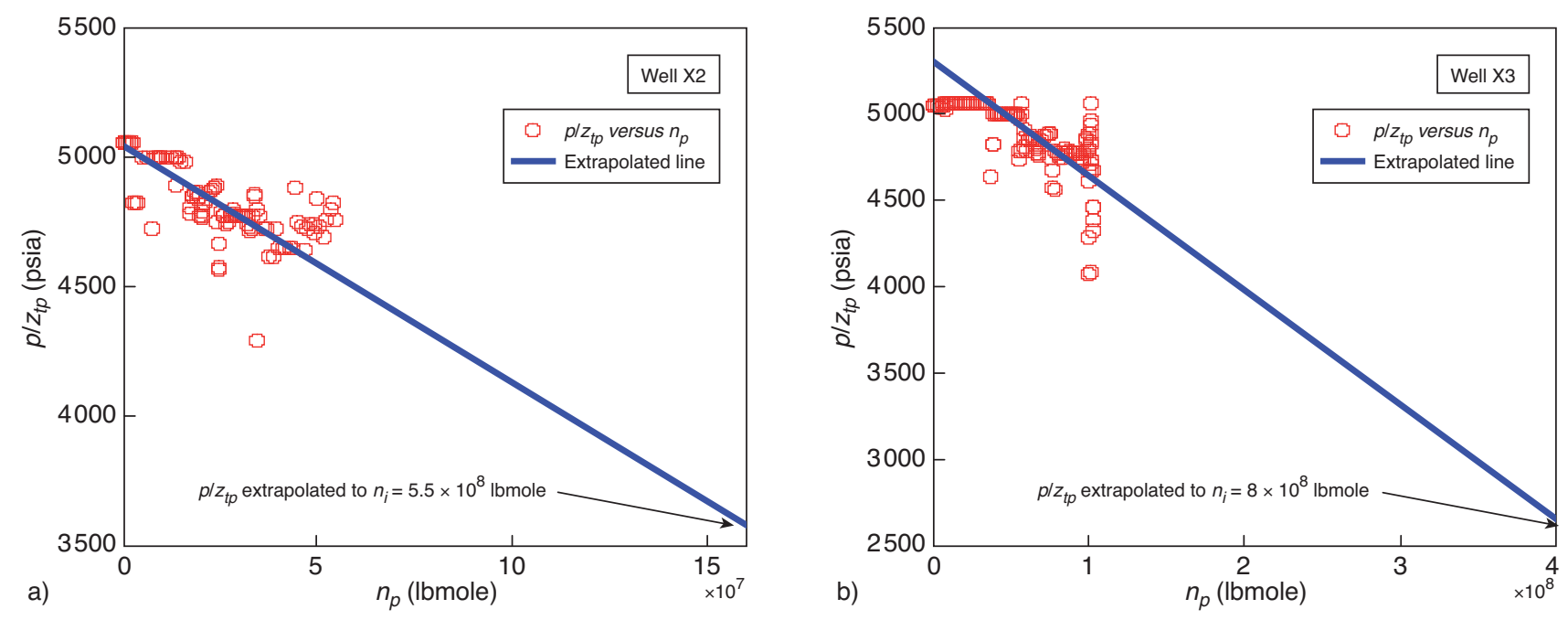

Figure 8

Plot of $p / z_{t p}$ evaluated at the pressures calculated in the first step of procedure versus cumulative mole production for a) well X2, b) well X3.

in Figure 8. It should be noticed that the early flat part of data in Figure $8 b$ should be ignored in straight line fitting. Although producing gas-oil ratio data are somewhat scattered, we still can detect a general increasing trend. Actually we should notice that production data are low quality, noisy and uncontrolled data which are gathered over the years. Therefore, preliminary treatments and data viability must be performed before analysis. A good discussion about such tasks has been performed by Ilk et al. (2010). In the reported producing gas-oil ratio data for this field, we can simply ignore few data points which show terrible deviation from the majority of the data. Eliminating such data causes extrapolated lines in Figure 8 to be less hazardous than what appears at the first look. For line fitting we have disregarded some of the data but here in the figures all data points are shown. After eliminating such data, we have determined two straight lines which present lower bound and upper bound for estimating gas in place. In another word, we are dealing with a region enclosed between these lines rather than a unique line. Then, we considered a line which is exactly in the center of the determined lower and upper bound lines and this is the line that we finally choose to determine gas in place, as plotted in Figure 8. The obtained gas in place values for drainage volumes of wells are $G_{\mathrm{X} 2}=208$ MMMscf and $G_{\mathrm{X} 3}=302 \mathrm{MMMscf}$. The total gas in place of the field is the summation of these two values which is $G=510$ MMMscf. The calculated $G$ with the use of volumetric method for this field is known to be $G=568.88$ MMMscf which is in good agreement with the estimated value using the mentioned procedure. Engineering methods for estimating reservoir parameters always have some degree of uncertainty and the proposed method here is not different. Actually no one can claim that any specific method gives the exact answer. That is why reservoir engineers should not rely only on one method and other sources of information must be employed along with the used analysis method. Since the size of the studied reservoir is rather small and the wells have produced for a long time, we have assumed that the drainage volumes of the wells cover the entire reservoir pore volume containing hydrocarbon. In reality, the wells may interfere and no-flow boundaries might be displaced. However, literature reveals



Figure 9

Average pressure for drainage volume of well X2, X3 and entire reservoir. 
that the assumption of considering fixed no-flow boundaries works well in many cases and it is the basis of many analytical methods which are already in use for production analysis. Using such assumption, we can simply add gas in place inside drainage volume of each well to obtain total gas in place. The agreement between the obtained gas in place and that of the volumetrically calculated one confirms the validity of this assumption. Figure 9 shows the calculated average pressure for drainage volumes of wells X2 and X3 and reservoir as well. To obtain average pressure of the reservoir, we used a simple weighing using the estimated gas in place and average pressures for drainage volumes of wells X2 and X3.

\section{CONCLUSIONS}

A simple method was presented to determine original gas in place and average reservoir pressure in gas-condensate reservoirs. The method uses flowing well data (gas production rate and producing gas-oil ratio) and there is no need to shut-in the well to determine average reservoir pressure. It provides a practical engineering tool for industry studies as it requires data which are generally available in normal production operations. The method was used to analyze synthetic production data and it was observed that the introduced errors were reasonable. It was also observed that the early production data cannot be analyzed using the proposed method but dry gas approach works well for analysis of early part of such data. The introduced method was further applied to a real gas-condensate field example. The obtained gas in place using the mentioned procedure was in agreement with the volumetrically calculated value for this field.

\section{REFERENCES}

Blasingame T.A., Lee W.J. (1986) Variable-Rate Reservoir Limits Testing, SPE paper 15028, presented at the Permian Basin Oil and Gas Recovery Conference, Midland, TX, 13-14 March.

Fevang Ø., Whitson C.H. (1995) Modeling Gas-Condensate Well Deliverability, SPE 30717, Annual Technical Conference and Exhibition, Dallas, 22-25 October.

Ilk D., Anderson D.M., Stotts G.W.J., Mattar L., Blasingame T.A. (2010) Production-Data Analysis-Challenges, Pitfalls, Diagnostics, SPE Reserv. Evalu. Eng. 13, 3, 538-552.

Hagoort J. (1988) Fundamentals of Gas Reservoir Engineering, Elsevier, Amsterdam.

Heidari Sureshjani M., Gerami S. (2011) A New Model for Modern Production Decline Analysis of Gas-condensate Reservoirs, J. Can. Petrol.Technol. 50, 7/8, 14-23.

Mattar L., McNeil R. (1998) The "Flowing" Gas Material Balance, J. Can. Petrol. Technol. 37, 2, 52-55.

Mattar L., Anderson D. (2005) Dynamic Material Balance (Oil or Gas-in-place without shut-ins), Paper Petroleum Society 2005-113, presented at the Petroleum Society's 6th Canadian International Petroleum Conference, Calgary, Alberta, Canada, 7-9 June.

Mott R. (2003) Engineering Calculations of Gas-Condensate-Well Productivity, SPE Reserv. Eval. Eng. 6, 5, 298-306.

Palacio J.C., Blasingame T.A. (1993) Decline Curves Analysis Using Type Curves: Analysis of Gas Well Production Data, SPE 25909, presented at the 1993 SPE Rocky Mountain Regional/Low Permeability Reservoirs Symposium, Denver, CO, 12-14 April.

Vo D.T., Jones J.R., Camacho-V R.G., Raghavan R. (1990) A Unified Treatment of Material Balance Computations, SPE 21567, CIM/SPE International Technical Meeting, Calgary, Canada 10-13 June.

Final manuscript received in February 2012 Published online in January 2013 